\title{
Os Estudos Fonético-Fonológicos no Estado do Ceará
}

\author{
Maria do Socorro Silva de ARAGÃO \\ Universidade Federal do Ceará (UFC)
}

\section{Introdução}

Estudar os falares regionais nordestinos, sob os aspectos fonético-fonológico e léxico, tem sido, desde alguns anos atrás, nossa principal preocupação. Tal escolha não se deve apenas à nossa origem, mas pelo desejo de descobrir se as variações da língua portuguesa falada no nordeste são realmente regionais - diatópicas -, hipótese esta sempre aventada pelos estudiosos do assunto, ou se são muito mais sociais diastráticas -, não marcando, assim, uma região, mas uma classe social, a dos menos escolarizados.

O português falado no Ceará vem sendo analisado não só por especialistas cearenses, como, também, por pesquisadores que chegaram ao estado com o propósito de dar continuidade a esses estudos. Tais trabalhos seguem uma longa tradição de professores e estudiosos, quer da área de letras, quer de outras áreas, todos, porém, com o objetivo dos mais proveitosos, de coletar dados e informações para a análise do falar cearense nos seus aspectos fonético-fonológicos e léxicos, entre outros.

\section{Os Estudos Lingüísticos no Ceará}

Como afirmamos anteriormente, o Ceará tem uma grande tradição de estudos lingüísticos, especialmente no campo da dialetologia, da sociolingüística e da lexicografia.

Tais trabalhos, na grande maioria, foram feitos por pesquisadores que, apesar da qualidade e do pionerismo de seus 
trabalhos, não seguiram uma metodologia científica que nos assegure sua pertinência, como bem frisa Monteiro (1988-90, p .69):

O que há, na verdade, é uma falta de divulgação de uma série de estudos bem intencionados, embora nem sempre realizados com rigor cientifico.

Ao estudar as fontes bibliográficas para o estudo do falar cearense, Monteiro (1988-90, p. 70) classifica-as nas seguintes categorias:

a) pesquisas sobre o português do Brasil; b) estudos sobre o folclore cearense; c) obras de caráter regionalista; d) textos de cantadores e poetas populares; e) ensaios e estudos sobre o falar cearense; f) dicionários de termos populares.

Aqui, apenas faremos referências aos trabalhos listados no item ensaios e estudos sobre o falar cearense. Neste aspecto, nomes como Martins de Aguiar (Fonética do português do Ceará, in: Repasse crítico da gramática portuguesa); Antônio Sales (O falar cearense) e Florival Seraine (Contribuição ao estudo da pronúncia cearense, in: Estudos cearenses; Introducão ao atlas lingüístico e folclórico do Ceará; Relaçoes entre niveis de norma na fala atual de Fortaleza; A relação do Maranhão do Padre Luís Figueira, entre outros), surgem como precursores dos estudos lingüísticos, especialmente os fonéticos, do falar do Ceará.

Num passado mais recente, surgem as dissertações de Mestrado e outros trabalhos de professores e pesquisadores das Universidades Federal e Estadual do Ceará, abordando aspectos variados do português padrão e não-padrão do Ceará. Entre eles, destacaríamos José Rebouças Macambira, Hamilton Cavalcante, José Lemos Monteiro e Antônio Luciano Pontes.

Atualmente, projetos como o do Atlas Lingüístico do Ceará, o da Norma Urbana Culta de Fortaleza, o do Português Nãopadrão do Ceará e o dos Dialetos Sociais Cearenses, entre outros e as novas Dissertações de Mestrado e Teses de Doutorado de professores 
e alunos das Universidades Federal e Estadual do Ceará, têm estudado aspectos específicos, não apenas fonéticos, mas também léxicos e morfossintáticos do português culto e popular do Ceará, utilizando as mais diferentes correntes da lingüística moderna.

Concordamos, portanto, com Monteiro (1988-90, p. 87) quando diz:

... somos de opinião que o Ceará já conta com um número apreciável de fontes bibliográficas para estudos e descrições lingüisticas.

\section{Os Estudos Fonético-Fonológicos no Ceará}

Dentre os trabalhos sobre o falar cearense que tratam dos aspectos fonético-fonológicos, destacaríamos, por seu pioneirismo, os trabalhos de Aguiar (1937) e de Seraine (1984) e, por sua atualidade, os trabalhos de Roncarati (1988) e Aragão (1996 - 1997).

\subsection{Trabalhos pioneiros}

\subsubsection{Martins de Aguiar}

O trabalho de Martins de Aguiar sobre aspectos fonéticos do falar do Ceará é um marco nesse tipo de análise, não só pela pesquisa realizada, mas, principalmente, pela análise que procedeu, tendo-se em conta o período em que foi feita e a falta de métodos e técnicas de que se dispõe hoje em dia. O trabalho cobre praticamente todos os pontos importantes onde o português falado no Ceará se distingue do falado em outras regiões do país, especialmente no sul e sudeste. Vale ressaltar que as pesquisas fonético-fonológicas realizadas atualmente vêm demonstrando que há muito mais uma variação sociocultural do que uma variação regional no português do Brasil.

O autor dividiu sua análise com as vogais de um lado e algumas consoantes de outro. No caso das vogais, ele trabalha com as 
orais / $a, e, i, o, u /$, as nasais / $\hat{e}, \hat{i}, \hat{u} /$. As consoantes analisadas são: / 3, K, n, r, s, v, z /, os ditongos / ay, aw, ãw, ey, ew, ow, oy /.

a) Vogais, Consoantes e Semivogais

- Vogal [a ] passa a [e ]

Raimundo [ ray'mûdo > rey'mûdo ]

Escandaloso [ eskãda'lozu > eskãde'lozu ]

- Vogal $[\varepsilon]$ passa a $[$ a $]$

Alemão [ ale'mãw $>$ ala'mãw ]

Ipapeconha [ pape'kôna > papa'kôna ]

- Neutralização das vogais [e ] e [i ]

Tear [ te'ah > ti'ah ]

Menino [ me'ninu $>$ mi'ninu ]

- Vogal [ e ] final passa a [a ]

Pele ['peli > 'pela - 'peאa ]

- Vogal [ê ] nasal, passa a [i ]

Bobagem [ bo'bazêy > bo'bazi ]

Imagem [i'mazêy $>$ i'mazi ]

- Vogal [i ] passa a [ $\varepsilon$ ]

Diferença [ dife'rêsa $>$ def $\varepsilon^{\prime}$ rêsa ]

Diploma [ di'plôma $>$ d $\varepsilon^{\prime}$ plôma ]

- Vogal [o ] passa a [û ]

Cozinha [ ko'zîna > kû'zîna ]

Governo [ go'vefinu > gû'vefinu ]

- Neutralização das vogais [o ] e [u ]

Poeta [ po'eta > pu'cta ]

Boneca [ bo'neka > bu'neka ] 
- Vogal [ û ] passa a [î̀]

Umbigo [ û'bigu $>$ î'bigu ]

Unguento [ û'gwêtu > 1̂'gwêtu ]

- Semivogal [w] passa a [ f ]

Desculpar [ deskuw'pah > deskuh'pa ]

- Semivocalização do [ $1>\mathrm{w}$ ]

Capital [ kapi'tal > kapi'taw ]

- Monotongação de [wa > 0 ]

Quaresma [kwa'rezma > ko'rezma ]

Quarenta [kwa'rêta $>$ ko'rêta ]

- Monotongação de [ yu > u ]

Palácio [ pa'lasyu $>$ pa'lasu ]

Relógio [ rélozyu $>$ re'lozu ]

- Monotongação de [ ay > a ]

Baixa [ 'bayfa > 'bafa ]

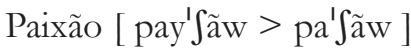

- Monotongação de [ aw > 0 ]

Piauí [ piaw'i > pio'i ]

- Monotongação de [ãw > o ]

Órgão [ 'ofigãw > 'ofigo ]

Órfão ['ohfãw > 'ohfo ]

- Monotongação de [ ey > e ]

Manteiga [ mã'teyga $>$ mã'tega ]

Almeida [ aw'meyda $>$ aw'meda ] 
- Monotongação de [ ew > 0 ]

Europa [ ew'ropa $>$ o'ropa ]

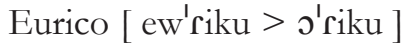

- Monotongação do ditongo [ ow > o ]

Ouro [ 'owru > 'oru ]

Ouço ['owsu > 'osu ]

- Ditongação de / a > ãy /

Sangue [ 'sãgi > 'sãygi]

- Ditongo [ ow ] passa a [ oy ]

Louça ['lowsa > 'loysa ]

Outubro [ ow'tubru > oy'tubru ]

- Iotização / aa > ay /

A água [ a 'agwa $>$ ay 'agwa ]

- Nasalização do [ $\mathrm{i}>\hat{i}]$ depois de [ $\mathrm{d}$ ou 1$]$

Idiota [ idi'ota $>$ idi'ota ]

Ilustre [i'lustri $>\hat{i}^{\prime}$ lustri ]

- Apagamento da vogal [i] átona

Experimentar [ ezperimê'tah > ezpefimê'tah ]

- Apagamento da vogal [o ] final

Veio ['veyu $>$ 'vey ]

Meio ['meyu > 'mey ]

- Consoante [3] passa a [6]

Jumento [ $3^{\prime}$ 'mêtu $>$ hu'mêtu ]

Gente ['3êti > 'hêti ] 
- Consoante [1] passa a [ $K$ ]

Família [ fa'milya $>\mathrm{fa}^{\prime} \mathrm{mi} K \mathrm{~K}$ ]

Mobília [ mo'bilya $>$ fa'miKa ]

- Acréscimo de [i ] após ou antes do [1]

Dificuldade [ difikul'dade $>$ difikuli'dadi ]

Implicar [ îpli'kah > îpili'kah ]

- Iotização do $[K>y]$

Velha [ 'veKa > 'veya ]

Telha [ 'te Ka $>$ 'teya ]

- Apagamento do $[\Lambda]$

Milho [ 'miKu > 'mil ]

- Despalatalização do $[K>1]$

Dou-lhe ['dow $K \mathrm{i}>$ 'dowli ]

Pilhéria [ pi'Kerya > pillerya ]

- Apagamento do [n] restando a nasalização

Tỉnha ['tîna $>$ 'tîa ]

Minha ['mîna > 'mîa ]

- Apagamento do [r] em posição final

Trabalhar [ traba'Kah > traba'Ka ]

- Mobilidade do [ $\mathrm{r}$ ] nas sílabas iniciais per e pre

Preciso [ pre'sizu > pef'sizu ]

Pergunta [ pefi'gûta $>$ pré'gûta ]

- Consoate [r] em final de sílaba, passa a [y]

Corneta [ kof'neta $>$ koy'neta ]

Perto [ 'pehtu $>$ 'p $\varepsilon y t u$ ] 
- Consoante [r] passa a [1]

Garça ['gahisas > 'gawsa ]

- Consoante [ s ] passa a [r]

Mesmo ['mezmu > 'mefum ]

As mangas [as 'mãgas $>$ ah 'mãga ]

- Apagamento da consoantes [s] em posição final

Os livros [ us 'livfus > us 'livfu ]

- Consoante [v] passa a [ h ]

Estava [if'tava $>$ if'tahia ]

Vamos [ 'vâmus > 'hâmus ]

- Consoante [v] passa a [b]

Varrer [ va'reh $>$ ba'reh ]

Verruga [ $v \varepsilon^{\prime}$ ruga $>b \varepsilon^{\prime}$ ruga ]

- Consoante [z ] passa a [ $\mathrm{h}]$

Fazenda [ fa'zêda $>$ fa'hêda ]

Fazer [ fa'zeh > fa'he ]

b) Outros Fenômenos

- Abertura das vogais pretônicas [ $\varepsilon$ ] e [0]

Secretária [ sekre'tarya ]

Loção [ lo'sãw ]

- Aférese

Afastar [ afaS'tah $>$ fas'tah ]

- Prótese

Voar [ vu'ah $>$ avu'ah ]

Sentar [ sếtah > asếtah ] 
- Neutralização do [ $\hat{e}>\hat{1}]$

Engenho [ ếzênu $>$ î'zênu ]

Então [ $\hat{e}^{\prime}$ tãw $>\hat{1}^{\prime}$ tãw ]

- Neutralização do [ $\hat{a}>\hat{1}]$

Ambição [ âbi'sãw > îbi'sãw ]

- Queda do [d] do grupo [-nd ]

Ficando [ fi'kâdu $>$ fi'kânu ]

Correndo [ ko'rêdu $>$ ko'rênu ]

- Queda da vogal postônica das proparoxítonas

Víbora ['vibora > 'vibra ]

Pássaro [ 'pasaru > 'pasru ]

- Queda da vogal postônica e da consoante final das proparoxítonas

Sábado [ 'sabadu > 'sabu ]

Lâmpada [ 'lâpada > 'lâpa ]

- Assimilação regressiva

Tábua [ 'tabwa $>$ 'tawba ]

Pátio ['patyu > 'paytu ]

\subsubsection{Florival Seraine}

Florival Seraine não foi um lingüista no sentido estrito do termo, uma vez que de profissão era médico. Contudo, dedicou-se durante muito tempo ao estudo da língua e da cultura nordestinas, especialmente a cearense. Seus trabalhos vão desde o estudo dos aspectos fonético-fonológicos e léxico da língua, passando pelos regionalismos e arcaísmos, até o estudo das várias manifestações artístico-culturais do povo cearense. 
Aqui trataremos, apenas, de seus estudos de fonética e fonologia do falar do Ceará, que, em grande medida, seguiram a mesma orientação dada por Martins de Aguiar em seus trabalhos. Muitos dos aspectos analisados por Aguiar foram retomados e confirmados por Seraine, razão pela qual não nos deteremos mais aprofundadamente nos mesmos. Veremos alguns dos pontos mais relevantes de suas análises:

a) Vogais, Consoantes e Semivogais

- Monotongação do ditongo [ ay> a ]

Caixa ['kaysa $>$ 'kafa ]

Baixa ['bayfa $>$ 'bafa ]

- Monotongação de [ey > e ]

Aldeia [ aw'deya $>$ aw'dea ]

Cheia [ 'Seya > 'Sea]

- Monotongação de [ wa > 0 ]

Quaresma [ kwa'rezma > ko'rezma ]

Quarenta [ kwa'rêta $>$ ko'rêta ]

- Monotongação de [ ow > o ]

Ouro ['owru $>$ 'oru ]

Couro ['kowru $>$ 'koru ]

- Ditongação da consoante [ u > uy ]

Fruta ['fruta $>$ 'fruyta ]

Luta ['luta > 'luyta ]

- Iotização da consoante [ $r>y$ ]

Porco [ 'pohku $>$ 'poyku ]

Cercado [ sef'kadu > scy'kadu ] 
- Iotização da consoante [ $1>$ y ]

Salgado [ saw'gadu $>$ say'gadu ]

Culpado [ kuw'padu $>$ kuy'padu ]

- Iotização da consoante $[\mathrm{n}>\mathrm{y}]$

Tamanho [ tâ'mânu > tâ'mãy ]

Ponho ['pônu > 'pôyu ]

- Troca do [1] por [ r ] nos grupos consonantais

Flexa [ 'flefa > 'frefa ]

Planta ['plâta $>$ 'prâta ]

- Neutralização das vogais [o ] e [ u ]

Coberta [ ko'befita $>$ ku'befita ]

b) Outros Fenômenos

- Aférese

Acostumado [ akuftu'madu $>$ kuftu'madu ]

- Síncope

Xícara ['Sikara > 'Sikra ]

- Epêntese

Cotovia [ kutu'via > kutru'via ]

- Hipérteses

Ceroula [ si'rola $>$ si'lora ]

- Apócope

Ridículo [ ri'dikulu $>$ ri'diku ]

- Prótese

Juntar [ $3 \hat{u ̂}^{\prime} \operatorname{tah}>$ azû'tah ] 
- Assimilação

Alemão [ ale'mãw > ala'mãw ]

- Dissimilação

$$
\text { Manhã [ mấnã > mê'nã ] }
$$

\subsection{Trabalhos atuais}

A nova leva de trabalhos sobre os aspectos fonéticofonológicos do falar do Ceará está ligada não só a pesquisas de caráter mais técnico-científico e, em alguns casos, são Teses e Dissertações de Mestrado, tendo, por isto mesmo, alguns cuidados metodológicos mais apurados que os anteriores não tiveram, sem que isto lhes tire, contudo, o valor e a importância. Entre os trabalhos atuais destacaríamos o de Cláudia Nívea Roncarati de Souza sobre o Enfraquecimento das fricativas sonoras (1988), o de José Auber Uchôa, sobre A sinalização de limites e conexões sintagmáticas por elementos prosódicos no dialeto de Fortaleza (1996), o de Maria Silvana Militão de Alencar, sobre $A$ linguagem regional popular na obra de Patativa do Assaré: aspectos fonéticos e lexicais (1977) e os de Maria do Socorro Silva de Aragão, sobre $A$ despalatalização e conseqüente iotização no falar de Fortaleza (1996) e O uso das proparoxitonas no falar de Fortaleza (1997).

Esses trabalhos têm um corpus bastante homogêneo, de falantes de pouca escolaridade, de zonas urbana e rural, homens e mulheres e de classe social de nível médio e baixo. Por se assemelharem quanto aos objetivos e ao tipo de análise, trataremos apenas de dois: o de Roncarati (1988) e o de Aragão (1996).

\subsubsection{Cláudia Nívea Roncarati de Souza}

Os trabalhos de Roncarati e Aragão foram feitos a partir do corpus da pesquisa dos Dialetos Sociais Cearenses, com informantes de faixas etárias, sexo, escolaridade e classe sociais bem delimitados. 
Ao iniciar seu trabalho, a autora faz um histórico dos estudos sobre o enfraquecimento das fricativas sonoras, citando, inclusive, Aguiar e Seraine, por nós já referidos. Os objetivos de seu trabalho foram, entre outros, o de descobrir que contextos lingüísticos e pragmáticos determinam ou facilitam o enfraquecimento e ou apagamento das fricativas sonoras / v, z, 3 /, observando, também, o nível de estigmatização desses fenômenos no grupo social onde os informantes estão inseridos, servindo o teste de atitude lingüística para caracterizar e classificar os informantes em termos de escolaridade e posição social.

Para compor sua amostra, a autora estabelece dois tipos de fatores que podem influenciar ou determinar o enfraquecimento e o apagamento das fricativas sonoras:

- Fatores Sociais: sexo, escolaridade, idade, classe social, procedência (urbana, rural) e estigmatização.

- Fatores Lingüísticos: distância da tonicidade, qualidade vocálica, consoante seguinte, usualidade do item lexical.

Feitos os levantamentos, o corpus ficou assim constituído: 4.066 casos de enfraquecimento das fricativas sonoras e 508 casos de apagamento dessas fricativas. Os resultados, muito bem comprovados estatisticamente, mostraram as seguintes conclusões:

- Fatores Lingüísticos para o enfraquecimento e ou apagamento:

- Natureza da vogal seguinte;

- Natureza da consoante seguinte;

- Presença do morfema do imperfeito -ava;

- Distância da tonicidade. 
a) Consoante / v /

- O enfraquecimento ocorre mais antes de / a /

$$
\text { Tava [ 'tava }>\text { 'taha ] }
$$

- O enfraquecimento ocorre mais com verbos no imperfeito do indicativo

$$
\text { Estava [i } \int^{\prime} \text { tava }>\text { if 'taha ] }
$$

- O enfraquecimento ocorre mais no verbo ir Vamos [ 'vâmus > 'hâmus ]

- O enfraquecimento ocorre mais na posição inicial do que na medial

Vem [ 'vêy > 'hêy ]

Inverno [ $\left.\hat{1}^{\prime} \mathrm{v} \varepsilon \mathrm{fnu}>\hat{i}^{\prime} \mathrm{h} \varepsilon \mathrm{finu}\right]$

- O apagamento ocorre mais com a vogal / o /

$$
\text { Você [ vo'se > Øo'se ] }
$$

b) Consoante / z /

- Enfraquecimento maior com a vogal / e /

Mesmo ['mezmu > 'mefum ]

- Enfraquecimento maior com o ditongo oral / ay / Mais ['mayz > 'mayh ]

c) Consoante / $3 /$

- Enfraquecimento maior em posição inicial Já ['3a> 'ha ] 
- O apagamento ocorre mais com a vogal nasal / ê /

Gente ['3êti > 'hêti ]

- Fatores Sociais que favorecem o enfraquecimento e ou apagamento:

- Nivel de formalidade: fala mais relaxada, mais rápida e menos monitorada, favorece o enfraquecimento e apagamento;

- Itens lexicais mais usuais;

- Relevância informacional e economia lingüística.

O trabalho, bastante longo e completo, desenha um amplo quadro do comportamento das consoantes / v, z, 3 / no falar do Ceará, complementando, assim, o que já havia sido feito nesse sentido por outros autores.

\subsubsection{Maria do Socorro Silva de Aragão}

Nossa experiência sobre aspectos fonético-fonológicos de falares nordestinos vem de longos anos de dedicação e trabalho no estado da Paraíba, onde realizamos, inclusive, as pesquisas e a publicação do Atlas Lingüístico da Paraíba.

Dentre os trabalhos sobre o falar do Ceará escolhemos aquele que se refere ao fenômeno da palatalização, iotização e apagamento das consoantes $/ \Lambda / \mathrm{e} / \mathrm{n} /$.

O fonema / $K /$ é descrito fonética e fonologicamente como consoante oral, sonora, lateral, dorso-palatal e o fonema / n / como consoante vibrante, sonora, nasal, dorso-velar. ambos ocorrem sempre em posição medial de sílaba medial, ou final de palavras e, com raríssimas exceções, em posição inicial de alguns empréstimos espanhóis e no pronome de 3 . $^{a}$ pessoa "lhe". Ao tratar da posição das consoantes / K / e / j / nas palavras, Câmara Jr. (1972, p. 38) considera a posição não-intervocálica de / $1-K / \mathrm{e} / \mathrm{n}-\mathrm{n} /$ uma neutralização. 
Em determinados contextos, por facilidade ou relaxamento de articulação o $/ K / \mathrm{e} o / \mathrm{n} /$ podem perder o traço palatal, passando a ser articulados como alveolares / 1 / e / n /, como iode / y / ou sofrer apagamento, desaparecendo.

Autores há que consideram esse fato um fenômeno fonético. Outros acham que é um problema de influência africana, uma mudança fonética do latim para o português, ou ainda um fato que pode vir a ser fonológico, gerando um novo fonema e não apenas uma articulação diferente dos fonemas / $\Lambda / \mathrm{e} / \mathrm{n} /$.

A despalatalização, definida como perda de traço palatal na articulação de um fonema, pode ser vista também como variedade regional, social, estilística ou individual.

Ao falar da iodização/iotização como um dos fatos decorrentes da despalatalização, explica Jota (1976, p. 179) que ela precede a palatalização na passagem do latim para o português.

Já Melo (1981) considera a despalatalização um caso sociolingüístico, de registro de linguagem popular, de pessoas incultas.

Para Câmara Jr. (1979), a despalatalização pode, muitas vezes, ser um fato fonológico, já que podemos ter mudança de significado do signo, tanto no caso de despalatalização / $\Lambda>1 /$ como com a iotização $/ \Lambda>y /$.

Outra hipótese para a despalatalização e iotização do / $\mathrm{K} / \mathrm{e}$ do / $\mathrm{n}$ / é a da influência do português crioulo dos escravos ou do substrato indígena, como diz Câmara Jr. (1979), hipótese esta também levantada por outros estudiosos que vêem a despalatalização e a iotização como uma marca da fala dos índios e africanos, que tinham dificuldades de articular o $/ \Lambda /$ e o $/ \mathrm{n} /$, como frisa Silva Neto (1877).

Historicamente, pode-se também explicar o fenômeno, uma vez que na passagem do latim para o português a iotização antecede a palatalização. Assim, em latim, havia o iode, que se palataliza no português como nos casos de milia $>$ milya $>$ milha ou foleam $>$ folha ou somnium $>$ sonho, sendo que $/ 1+\mathrm{y} / \operatorname{deram} / \Lambda / \mathrm{e} / \mathrm{n}+\mathrm{y} /$ $\operatorname{deram} / \mathrm{n} /$. 
Ora, no caso da despalatalização, que leva à iotização, o movimento se inverteu, ou seja, o $/ K /$ desdobra-se em $/ 1+$ y $/$ e o $/ \mathrm{n} / \mathrm{em} / \mathrm{n}+\mathrm{y} /$.

Quanto ao apagamento do $/ \Lambda>\varnothing / \mathrm{e} / \mathrm{n}>\varnothing /$, os autores não têm dado a isso muita ênfase, com exceção de Aguilera (1994), que registra o fato no falar do Paraná, porém com ocorrência mínima, a não ser em palavras específicas como "silhão" e "trilho".

As primeiras análises do fenômeno, no falar do Ceará, indicam alguns fatos como os mostrados a seguir:

- Apagamento do / $\mathrm{n} /-/ \mathrm{n}>\varnothing /$

No corpus estudado, há uma predominância, quase que absoluta, do apagamento do / $\mathrm{n} /-/ \mathrm{n}>\varnothing /$ antecedido da vogal fechada / i /, em sílaba nasal, restando, contudo, a nasalização, como nos casos de:

$$
\begin{aligned}
& \text { Minha [ 'mîna > 'mĩa } \\
& \text { Caminho [ kâ'mînu > kâ'mĩ }
\end{aligned}
$$

- Permanência do / $\Lambda$ /

Fato marcante, também nesse contexto, é a permanência do $/ \Lambda /$ tanto em sílaba medial quanto em final, como nos exemplos:

Milho ['miKu ]

Melhora [mi'אora ]

Brincalhona [ brikikâôna ]

- Permanência do / n /

O fonema / $\mathrm{n} /$, permanece em sílaba medial e final, como nos exemplos:

Escolinha [ isko'lîna ]

Conheço [ku'nesu ]

Sonhado [ so'nadu ] 
- Iotização do / $\Lambda$ /

Em seguida, em número de ocorrências, vem a iotização do / $\Lambda$ /, em sílabas medial e final, como nos exemplos:

Filho ['fiKu > 'fiy ]

Milha [ 'mi Ka > 'miya ]

Trabalhador [ trabaKa'doh $>$ trabaya'do ]

- Iotização do / n /

$\mathrm{O} / \mathrm{n}$ / também sofre iotização em sílabas medial e final, como nos exemplos:

Banho [ 'bânu > 'bãy ]

Tenho ['tênu > 'tẽyu ]

Maconha [ ma'kôna > ma'kõya ]

Sonhado [ so'nadu ]

• Baixas Freqüências ou Não Ocorrências

Apesar de se esperar que ocorressem, alguns fatos não apareceram ou apareceram com uma única ocorrência em todo o corpus. São os casos de:

- Dupla iotização [ $K-\mathrm{n}>$ yy ] que apareceu em [ ga'Kînu > ga'Tiyyu ];

- Despalatalização simples do $[K>1]$, como em [ mu'Ke > mu'le ];

- No caso do [ $\mathrm{n}>\mathrm{n}$ ], não ocorreu em nenhum caso a despalatalização simples;

- Apagamento do $[K]$ não ocorreu em nenhum caso. 


\section{Conclusão}

Ao analisarmos os trabalhos sobre o falar do Ceará, nos aspectos fonético-fonológicos, independentemente de sua importância para os estudos dos falares regionais do português do Brasil, percebemos a similaridade entre os fatos analisados no Ceará com os mesmos fatos, ou quase os mesmos, nos falares de outros estados nordestinos e mesmo de outras regiões do país.

Isto vem corroborar a idéia, por mim também aceita, de que, do ponto de vista fonético-fonológico, os falares regionais do Nordeste não têm sua marca diatópica específica por serem do Nordeste ou de sua zona rural, mas têm as marcas diastráticas das variantes socioculturais de todo o país. Ou seja, não se fala de tal modo por se ser nordestino, quer cearense, quer paraibano, quer pernambucano, mas fala-se assim por se pertencer a uma classe social menos favorecida e com pouca escolaridade. Esta é a nossa hipótese, a qual estamos tentando confirmar, com trabalhos sobre os diferentes falares do português do Brasil.

\section{BIBLIOGRAFIA}

AGUIAR, Martins de. Fonética do português do Ceará. Revista do Instituto do Ceará, Fortaleza: 51(51): 271-307, 1937.

AGUILERA, Vanderci de Andrade. O fonema / K /: realização fonética, descrição e sua comparação na fala popular paranaense. In: ENCONTRO NACIONAL DE FONÉTICA E FONOLOGIA, 3., [1987 ou 1988]. João Pessoa: UFPB, 1988.

ANDRADE, Hamilton Cavalcante. O dialeto cearense. 1974. Dissertação (Mestrado). Pontifícia Universidade Católica do Rio de Janeiro, Rio de Janeiro. 
ARAGÃO, Maria do Socorro Silva de et al. A despalatalização e conseqüente iotização no falar de Fortaleza. JORNADA DE ESTUDOS LINGÜÍSTICOS DO GELNE, 14. 1996. Natal: UFRN, 30 out. a 01 nov. 1996.

O uso das proparoxítonas no falar de Fortaleza. In: JORNADA DE ESTUDOS LINGÜÍSTICOS DO GELNE, 15., 1997. Recife: UFPE, 25-28 nov. 1997.

.; SOARES, Maria Elias (Orgs.) A linguagem falada em

Fortaleza - Diálogos entre informantes e documentadores - materiais para estudo. Fortaleza: UFC, 1996.

CÂMARA JR., Joaquim Mattoso. História e estrutura da língua portuguesa. Rio de Janeiro: Padrão, 1979.

Estrutura da língua portuguesa. Petrópolis: Vozes, 1972.

JOTA, Zélio dos S. Dicionário de lingüística. Rio de Janeiro: Presença, 1976.

MACAMBIRA, José Rebouças. A estrutura silábica do português língua culta de Fortaleza. In: SEMINÁRIO DE ESTUDOS SOBRE O NORDESTE, 2., [1975?] Salvador: UFBA, 1975.

MELO, Gladstone Chaves de. A língua do Brasil. Rio de Janeiro: Padrão, 1981.

MONTEIRO, José Lemos. Fontes bibliográficas para o estudo do falar cearense. Revista da Academia Cearense de Língua Portuguesa. Fortaleza, anos 9-11, n. 9, p. 68-94, 1988-1990.

RONCARATI de SOUZA, Cláudia Nívea et al. Enfraquecimento das fricativas sonoras. Relatório Final: Projeto Dialetos Sociais Cearenses - Fortaleza: FINEP/FCPC/UFC, 1988.

SALES, Antônio. Notas de linguagem (o falar cearense). Almanaque do Estado do Ceará. Fortaleza: [s.n.], 1924. 
SERAINE, Florival. A relação do Maranhão do Padre Luís Figueira e o falar cearense atual. Revista do Instituto Histórico do Ceará. Fortaleza, 84 (81):21-55, 1970.

Relações entre níveis de norma na fala atual de Fortaleza. In: __ Linguagem e cultura - estudos e ensaios. Fortaleza: Secretaria de Cultura e Desporto, 1984.

Dicionário de termos populares (registrados no Ceará). Fortaleza: Stylus, 1991.

SILVA NETO, S.

UCHOA, J. A. A sinalização de limites e conexões sintagmáticas por elementos prosódicos no dialeto de Fortaleza. 1996. Dissertação (Mestrado) Universidade Federal do Ceará, Fortaleza. .; SOARES, Maria Elias (Org.) In: JORNADA DE ESTUDOS LINGÜÍSTICOS, 17., 1999. Programa e Resumos. Fortaleza: UFC/GELNE, 1999. 